\title{
Vidas entrelaçadas pela invisibilidade social: a formação da identidade docente no contexto situado da socioeducação
}

Lives intertwined by social invisibility: the formation of the teaching identity in the context of socioeducation

Vidas entrelazadas por la invisibilidad social: la formación de la identidad docente en el contexto situado de la socioeducación

Recebido: 19/06/2021 | Revisado: 29/06/2021 | Aceito: 01/07/2021 | Publicado: 14/07/2021

\author{
Willian Lazaretti da Conceição \\ ORCID: https://orcid.org/0000-0001-8143-6524 \\ Universidade Nova de Lisboa, Portugal \\ Universidade Federal do Pará, Brasil \\ E-mail: lazaretti@ufpa.br \\ Rubia Fernanda Quinelatto \\ ORCID: https://orcid.org/0000-0002-0827-3869 \\ Universidade Federal de São Carlos, Brasil \\ E-mail: rubiafq@gmail.com
}

\begin{abstract}
Resumo
$\mathrm{O}$ presente estudo de natureza qualitativa apresenta trajetórias de vida de professores(as) que lecionam para adolescentes autores(as) de ato infracional, que estão em cumprimento de medida socioeducativa de internação na Fundação Centro de Atendimento Socioeducativo ao Adolescente - FCASA, instituição responsável pela execução socioeducativa em meio fechado no Estado de São Paulo, apontar como as experiências influenciam na constituição da identidade docente e reverberam no fazer docente e nos projetos de vida de adolescentes. $\mathrm{O}$ método empregado foi a História Oral de Vida de doze professores(as) que lecionam em três Centros de Internação. O método foi crucial para compreender como suas histórias, desafios e conquistas colaboram para que adolescentes trilhem caminhos, com a referência de alguém que passou por situações similares e abandonou a condição de ser oprimido social. $\mathrm{O}$ artigo apresenta alguns nós górdios da educação e emerge a condição de efetivação das políticas públicas, no trato aprofundado dos Direitos Humanos.
\end{abstract}

Palavras-chave: Ensino; Socioeducação; Escola; Professor; História oral.

\begin{abstract}
This qualitative study presents the life trajectories of teachers who teach teenagers who commit criminal acts, who are in compliance with a socio-educational measure of hospitalization at the Foundation Center for Socio-educational Assistance to Adolescents - FCASA, the institution responsible for the socio-educational execution in a closed environment in the State of São Paulo, to point out how experiences influence the constitution of the teaching identity and reverberate in the teaching activities and in the life projects of adolescents. The method used was the Oral History of Life of twelve teachers who teach in three Internment Centers. The method was crucial to understand how their stories, challenges and achievements collaborate for teenagers to tread paths, with the reference of someone who went through similar situations and abandoned the condition of being socially oppressed. The article presents some Gordian knots of education and emerges the condition for the effectiveness of public policies, in the in-depth treatment of Human Rights.
\end{abstract}

Keywords: Teaching; Socio-education; School; Teacher; Oral history.

\section{Resumen}

Este estudio cualitativo presenta las trayectorias de vida de los docentes que enseñan a los adolescentes que cometen actos delictivos, que están en cumplimiento de una medida socioeducativa de hospitalización en la Fundación Centro de Atención Socioeducativa a la Adolescencia - FCASA, institución responsable de la ejecución educativa en un ambiente cerrado en el Estado de São Paulo, para señalar cómo las experiencias inciden en la constitución de la identidad docente y repercuten en las actividades docentes y en los proyectos de vida de los adolescentes. El método utilizado fue la Historia Oral de la Vida de doce profesores que imparten docencia en tres Centros de Internamiento. El método fue crucial para entender cómo sus historias, desafíos y logros colaboran para que los adolescentes transiten caminos, con la referencia de alguien que pasó por situaciones similares y abandonó la condición de ser socialmente oprimido. El artículo presenta algunos nudos gordianos de la educación y emerge la condición para la efectividad de las políticas públicas, en el tratamiento en profundidad de los Derechos Humanos.

Palabras clave: Ensenãnza; Socioeducación; Escuela; Docente; Historia oral. 


\section{Introdução}

O presente estudo apresenta reflexões acerca das aproximações e distanciamentos entre as histórias de vidas dos(as) professores(as) nos processos de ensino e de aprendizagem das relações intersubjetivas decorrentes do processo educacional escolar com adolescentes que se encontram em cumprimento de medida socioeducativa de internação na Fundação Centro de Atendimento Socioeducativo ao Adolescente - CASA, instituição executora de medidas socioeducativas em meio fechado do Estado de São Paulo, anteriormente denominada Fundação Estadual do Bem-Estar do Menor - FEBEM.

Nesse contexto situado, a oferta da educação escolar é constituída pela educação básica a contemplar os níveis de ensino fundamental e médio, visando garantir o acesso e permanência à política educacional, conforme previsto na resolução $\mathrm{CNE} / \mathrm{CEB} \mathrm{n}^{\circ} 3$, de 13 de maio de 2016, que define Diretrizes Nacionais para o atendimento escolar de adolescentes e jovens em cumprimento de medidas socioeducativas (Brasil, 2016).

Insta evidenciar que professores(as) que trabalhavam no espaço de educação regular, conforme política vigente quando da realização da pesquisa, não tinham vínculos efetivos com a Secretaria Estadual de Educação - SEE de modo que a continuidade do exercício dependia de avaliações semestrais, que possibilitavam ou não a recondução e, por conseguinte, a permanência nesses espaços daqueles(as) bem avaliados(as) considerando aspectos constantes no documento orientador (São Paulo, 2017) que será apresentado e discutido no decorrer do texto.

Esta explicação se faz pertinente, visto que em outras regiões do país, os(as) professores(as) possuem vínculos como efetivos(as) e inclusive recebem gratificações por ocuparem espaços escolares existentes nos contextos socioeducativos e prisionais. Tal configuração associada às condições salariais e de estabilidade possibilitam interpretações outras, em relação aos objetivos de ser professor(a) para adolescentes em cumprimento de medida de internação, possibilidades estas que não são objeto de análise deste artigo.

A proposta deste estudo caminha no sentido de propiciar contribuições para o debate sobre o que é ser docente no espaço situado da escolarização para adolescentes em cumprimento de medida socioeducativa de internação, tomando como base como as histórias de vida (Meihy; Holanda, 2013; Guimarães, 2011), tendo como hipótese que tais histórias influenciam na ação docente entre muros e grades, espaço tal que é repleto de idiossincrasias, atravessado veementemente pelas relações de poder, pelos sentidos atribuídos à escola pelos(as) adolescentes, pelo poder Judiciário, pela Fundação CASA e pelos(as) próprios(as) professores(as) e agentes socioeducativos, que participam do cotidiano do Centro de Internação - CI.

O presente artigo está organizado em três partes, no qual na primeira é apresentado o referencial teórico sobre o(a) adolescente em situação de privação de liberdade e as relações estabelecidas com a prática social escolar no decorrer das trajetórias de vidas e o lugar do(a) professor(a) nessas histórias. Cabe explicitar que a opção metodológica pelo uso da história oral como método (Meihy, 1996, 2008), oportuniza trazer passagens das narrativas e dialogar com o referencial teórico no decorrer do estudo. No segundo momento apresentamos o caminho metodológico percorrido no decorrer da pesquisa, formando a comunidade de professores(as) que colaboraram com a pesquisa e como a história oral se constituiu com método pertinente neste estudo. E, por fim, a terceira parte apresenta o entrelaçamento das narrativas coletadas ao longo do trabalho de campo, as impressões e os anseios dos(as) professores(as) acerca da ação docente no contexto situado da socioeducação, como as experiências influenciam nesse mo(vi)mento.

\section{Fundamentação Teórica}

Ao refletirmos acerca dos estudos e pesquisas sobre e com adolescentes em situação de privação e restrição de liberdade, é possível verificarmos que o tema tem adentrado à zona de visibilidade em nossa sociedade, todavia apenas após inúmeros problemas instaurados pelas diferentes mídias. As pesquisas nesta seara contam com pesquisadores(as) de diferentes áreas, como é possível verificar nas coletâneas organizadas por Conceição (2017a) e Fernandes e Peres (2019) e nas pesquisas 
de Müller, Oliveira e Conceição (2021), Campos et al. (2021), Oliveira et al. (2021a; 2021b).

Não obstante a organização desses livros, em uma análise não sistemática, é possível identificarmos pesquisas realizadas na pós-graduação stricto sensu contemplando as respectivas áreas do saber: Educação (Dias, 2007; Quinelatto, 2015, Conceição, 2017b), Teixeira, (2009, 2017), Educação Física (Müller, 2017; Oliveira et al., 2020), Sociologia (Almeida, 2010, Rolim, 2014, Teixeira, 2015, Rovaron, 2017), Antropologia (Moreira, 2011). Nesse texto, direcionamos o olhar às pesquisas que refletem acerca da educação e os(as) agentes envolvidos(as) diretamente com o processo educacional escolar.

Para balizar o processo escolar foi cunhado o Documento Orientador Conjunto elaborado pela Coordenadoria de Gestão da Educação Básica em parceria com a Fundação CASA, que explica o perfil adequado para os(as) profissionais envolvidos(as) no trabalho pedagógico com os(as) adolescentes em cumprimento de medidas socioeducativas:

1) $\mathrm{O}$ adolescente é pessoa em condição peculiar de desenvolvimento e deve ter seus direitos protegidos; 2) Não realizar pré-julgamentos, pois o adolescente já está em cumprimento de medida socioeducativa, judicialmente imposta; 3) Compreender as funções próprias da Educação escolar: é direito do adolescente o acesso à Educação Básica e dever do Estado garanti-lo. Assim, o foco é o ensino e aprendizagem e o cumprimento das funções próprias da Educação, na perspectiva da reinserção social e da promoção da cidadania; 4) Organização e preparação: o professor deve planejar as aulas e buscar estratégias para atuação com as classes, com apoio da escola vinculadora e Diretoria de Ensino, adaptando recursos e atendendo os 'Procedimentos de segurança' necessários ao acesso nos Centros da Fundação CASA; 5) Diálogo: promover um ambiente de diálogo, socialização de informações e difusão de conhecimentos, pautando, permanentemente, o respeito mútuo, a cooperação, a solidariedade e a cultura educacional (São Paulo, 2017, p.32).

A organização desse documento supre parte da inquietação apontada pela professora Carla, que ao refletir sobre a condição de ser docente no contexto situado da socioeducação, entendia que o poder público sequer tinha conhecimento acerca do perfil ideal, se é que existe, para ser docente em uma instituição que se assemelha em muitos aspectos à uma instituição total ${ }^{1}$. Segundo a professora "Falam na diretoria de ensino que tem que ter perfil, mas acho que eles nunca conseguiram saber qual é o perfil de um professor para trabalhar na Fundação CASA, tem que ser homem, tem que ser mulher" (Professora Carla).

O documento organizado pelas Secretarias, nos remete a diferentes posicionamentos que perpassam dispositivos legais, tais como a Constituição Federal quando trata da "[...] obediência aos princípios de brevidade, excepcionalidade e respeito à condição peculiar de pessoa em desenvolvimento, quando da aplicação de qualquer medida privativa da liberdade" (BRASIL, 1988, s/p), com o respeito necessário ao(à) adolescente que está em cumprimento de medida socioeducativa de internação, com a garantida dos direitos previstos no Estatuto da Criança e do Adolescente (Brasil, 1990), na Lei de Diretrizes e Bases da Educação (Brasil, 1994) e no Sistema Nacional de Atendimento Socioeducativo (Brasil, 2012), mas também às normas e condutas que são esperadas por parte de alguns(as) profissionais que trabalham na instituição, porém não coadunam com o projeto pedagógico institucional maior.

A escola que funciona dentro do espaço socioeducativo na Fundação CASA tem como normativa o documento orientador elaborado conjuntamente pela Coordenadoria de Gestão da Educação Básica em parceria com a Fundação CASA, que dentre outras questões, versa sobre a heterogeneidade das classes, com diferentes experiências de vida e trajetórias escolares e, sobretudo quando agrupam estudantes de diferentes anos/séries de um mesmo segmento (São Paulo, 2017).

No referido documento aborda a questão das classes multisseriadas e complementa que faz-se necessária uma organização e planejamento diferenciado por parte do(a) professor(a), com o apoio da coordenação pedagógica e da escola vinculadora. Ou seja, pelo exposto, a maioria dos Centros de Internação - CI, não possuem espaço físico para a constituição de

\footnotetext{
${ }^{1}$ Uma instituição total pode ser definida como um local de residência e trabalho onde um grande número de indivíduos com situação semelhante, separados da sociedade mais ampla por considerável período de tempo, leva uma vida fechada e formalmente administrada (Goffman, 2003, p. 11).
} 
classes que não sejam multisseriadas e, também de acordo com a normativa, o projeto pedagógico deve se balizar no currículo da rede que, por sua vez, é seriado. "Se eu pudesse, mudaria esse sistema de classes multisseriadas. Porque o professor, principalmente no começo fica de mãos atadas. O currículo é outro aspecto que é muito difícil. O professor dentro da Fundação tem que trabalhar o currículo do governo, das escolas daqui de fora. Não tem como você entrar numa sala de aula com quatro livrinhos de diferentes séries/anos do currículo, é humanamente impossível” (Professora Carla).

Este é um dos nós górdios da educação escolar na socioeducação, pensar em um currículo que atenda às especificidades deste contexto e pensar, também, sobre a continuidade do(a) adolescente após o encerramento do cumprimento da medida de internação, partindo do pressuposto que deverá continuar o seu processo de escolarização nas escolas externas à internação.

A classe multisseriada é alvo de crítica das professoras Carla, Maria Lala e Sinhá que relatam que dependendo do CI em que está, a situação fica mais complexa, pois não permitem que se façam trabalhos inovadores utilizando outros recursos que não apenas giz e lousa. Não obstante, ainda é obrigatório o uso do caderno do(a) aluno(a) com alunos(as) de diferentes séries/anos. Percebemos a responsabilização que é delegada à equipe pedagógica, com o enredo que essa decisão política visa favorecer a autonomia da coordenação pedagógica em colaboração com os(as) professores(as) e alunos(as) para que busquem estratégias que garantam educação de qualidade.

A escola tem sido objeto de investigação de profissionais que trabalham na socioeducação e de pesquisadores(as) que nunca puderam adentrar tal espaço, porém apresentam interesse em conhecer e investigar as práticas sociais existentes nos espaços de restrição e privação de liberdade. Notadamente, é possível verificarmos diferenças de como cada público concebe o cotidiano socioeducativo, ou seja, há um hiato entre experienciar como profissional-pesquisador(a) e pesquisador(a) externo. Embora não tencionemos qualificar ou desqualificar um ou outro é um aspecto que merece ser pontuado.

No que tange a escolarização é possível vislumbrar tal interpretação na pesquisa realizada por Fonseca (2013):

[...] a cada momento que o adolescente sai da sala de aula tem que se submeter à revista pessoal, sendo este procedimento justificado pelo fato de estarem em manuseio de "objetos considerados perigosos" pela instituição, quais sejam, lápis e canetas. O professor precisa se adequar a estas exigências e cumprir as regras da instituição, se submetendo à autoridade/poder dos agentes de segurança, bem como a contagem/conferência do material utilizado em aula, assim como, não permitir que alguns diálogos ocorram entre os alunos ou mesmo que possam fazer desenhos associados ao "mundo do crime" (Fonseca, 2013, p.21).

Ao analisar o excerto, apesar de ser de fato um ponto a ser problematizado, entende-se que não seja cabível, que apenas seja enunciado os pontos de tensão no processo educativo, não se trata, porém, de camuflar que seja um ambiente dotado de práticas hostis, entretanto, ao propor que seja um espaço educativo, ações são desenvolvidas na direção da justiça social (Conceição et al., 2020). Marzochi (2014) traz a narrativa de um adolescente que cumpria medida socioeducativa de internação:

Eu não sentia a escola na minha vida, sei lá, não queria fazer tarefa, só bagunçar, ficava com preguiça. Mas, depois que eu vim para cá eu comecei a me interessar mais, me esforçar mais, comecei a ver que daqui em diante minha vida seria ser isso que sou hoje (...). Aqui dentro eu tenho uma professora que me ajuda bastante. Eu vejo que ela é uma boa professora, me ajuda, tem interesse em desempenhar um bom trabalho (...) (Adolescente Bruno) (Marzochi, 2014, p.91).

O sentimento compartilhado por Bruno se associa em dois momentos ao relato da professora Luiza. No primeiro, quando a professora é alertada por colegas que lecionam nas escolas estaduais, acerca da dificuldade em conseguir desempenhar um bom trabalho diante das condições oferecidas pelo Estado, essencialmente pelas salas com muitos(as) alunos(as). No segundo momento, quando a professora nos diz que às vezes alguns(mas) alunos(as) apresentam dificuldades e começam a se calar em sala, dispersando a atenção, porém ao perceber tal conduta, Luzia buscava outras metodologias de 
ensino, conversando com adolescentes para entender a raiz da dificuldade, a qual, muitas vezes, consiste em conteúdos relacionados às series anteriores que não foram apresentados e/ou devidamente aprendidos.

Essa relação ao acolhimento e aproximação relatada pela professora Luiza, embora seja necessária em todas as escolas, se torna mais exequível quando o(a) adolescente está em cumprimento de medida de internação, na qual a classe, em alguns contextos, tem no máximo 20 alunos(as), enquanto nas escolas externas é possível nos depararmos com turmas com mais de 40 alunos(as) em sala de aula. De acordo com Fonseca (2013), a escola fora dos muros da privação de liberdade se configura como uma experiência negativa para ambos(as), alunos(as) e professores(as), pois nela vivenciaram situações de preconceito, violência e exclusão, que contribuem para o olhar que o(a) adolescente lança em relação à instituição escolar.

Essa situação de constrangimento que muitos(as) adolescentes vivenciam no espaço escolar também foram experienciadas por alguns(mas) professores(as), como é possível verificar na narrativa da professora Maria Lala: "Quando a professora pegou meu caderno para corrigir a lição, estava lá o bilhete, eu nem sabia ler, primeira, segunda série, a professora leu, em vez de ela guardar e ser uma comunicação entre elas, não, ela foi e falou para a sala toda e num tom sarcástico disse para ninguém chegar perto de mim que eu era filhinha da mamãe e do papai, e que ninguém não podia mexer nela, não podia tocar, ressaltando para as crianças não me tocarem na hora do recreio, não brincarem comigo".

Ao rememorar as experiências que tiveram no processo educacional escolar, os(as) professores(as) conseguem refletir e então passam a reproduzir ou refutar as condutas dos(as) docentes e, no caso da socioeducação essas reflexões subjazem às relações intersubjetivas que tencionam ser dialógicas à medida que conseguem compreender as dificuldades vivenciadas pelos(as) jovens antes do ingresso à internação.

\section{Caminho Metodológico}

O caminho metodológico, de caráter qualitativo, se dá pelos princípios da História Oral, tendo como base os autores Meihy (1991, 1994, 1996a, 1996b, 2008), Caldas (1999, 2008, 2009), Guimarães (2011), Meihy e Holanda (2013), Pereira, Quinelatto, Conceição (2021). A história oral utilizada enquanto um método de pesquisa faz com que as histórias de vida sejam o epicentro do trabalho. Para Meihy (1991) existem três etapas na passagem do oral para o escrito: a transcrição, a textualização e a transcriação da entrevista.

O processo é complexo e teve início com a estruturação do projeto definindo quem seriam os(as) entrevistados(as), o local para a realização das entrevistas, o tempo de duração, o processo de transcrição e conferência do texto, autorização para uso da entrevista, como e onde seriam arquivadas e as respectivas justificativas destas escolhas (Meihy; Holanda, 2013).

A organização do projeto teve início com a definição da comunidade de destino ${ }^{2}$, professores/as da Fundação CASA, que atuavam em CI de um determinado município e seriam convidados(as) a compor o quadro de colaboradores/as, a colônia ${ }^{3}$. Para tanto, foi considerado o tempo de docência do primeiro autor junto ao quadro docente, com efeito, formando-se a rede ${ }^{4}$ convidando àqueles/as que eram assíduos, que se preocupavam em planejar as aulas, participar dos projetos; em suma, os que de fato se engajavam com a proposta educativa. Neste recorte, foram convidados/as doze professores(as), tendo em vista que o processo de colaboração poderia ser mais fluído, necessário a uma comunidade de destino.

\footnotetext{
${ }^{2}$ A comunidade de destino tem duas bases, uma, material e outra psicológica. De uma ou de outra forma, a sustentação que marca a união de pessoas são dramas comuns, coetâneos, vividos com intensidade e consequências relevantes (Meihy; Holanda, 2013, P.51)

${ }^{3}$ Menor que a comunidade de destino, a colônia é fragmento substantivo, fração representativa, ainda que numericamente inferior à grande comunidade de destino. É parte dividida para possibilitar o entendimento do todo pretendido (Meihy; Holanda, 2013, P.53).

${ }^{4}$ É uma subdivisão da colônia, portanto a menor parcela de uma comunidade de destino. A origem da rede é sempre o ponto zero, e essa entrevista deve orientar a formação das demais redes. A indicação de continuidade das redes preferencialmente deve ser derivada da entrevista anterior (Meihy; Holanda, 2013, p.54). Nesta pesquisa, optamos por não seguir a proposição de Redes, mas de convidar as professoras e professores que haviam trabalhado com o pesquisador.
} 
[...] é preciso que se forme uma comunidade de destino para que se alcance a compreensão plena de uma dada condição humana. Comunidade de destino já exclui, por sua própria enunciação, as visitas ocasionais ou estágios temporários no lócus da pesquisa. Significa sofrer de maneira irreversível, sem possibilidade de retorno à antiga condição, o destino dos sujeitos observados (Bosi, 1994, p. 38).

As entrevistas foram realizadas com nove professoras e três professores que lecionavam para os(as) jovens em situação de privação de liberdade. O convite formal foi feito individual e presencialmente, exceto para dois professores, os quais foram convidados por e-mail: um porque não mais trabalhava nessa equipe e outra devido à incompatibilidade de horários de trabalho. $\mathrm{O}$ vínculo fraterno estabelecido, entre pesquisador com a maioria dos/as colegas ao longo dos anos facilitou a incorporação de requisitos éticos sobre os quais Portelli (1997) discorre que "[...] compromisso com a honestidade significa, para mim respeito pessoal por aqueles com quem trabalhamos, bem como respeito intelectual pelo material que conseguimos; compromisso com a verdade" (Portelli, 1997, p.15).

O sentido de colaboração aqui proposto não percebe pessoas como objetos de estudo, mas como propõe Oliveira et al. (2014) são participantes da pesquisa que co-laboram com a investigação realizada. Ainda sobre o uso do termo colaboração nesta pesquisa, trazemos a contribuição de Meihy e Ribeiro (2011), pois no caso da história oral o interlocutor está no centro gerador de visões.

Em relação à ética e ao respeito aos/às colaboradores/as tomamos as preocupações expostas por Denis (2008), tais como analisar os riscos e as contribuições do projeto, respeitar a cultura alheias e as formas de abordagem; para o autor, os contatos prévios determinam a qualidade de todo o processo: a apresentação dos objetivos da pesquisa, do termo de consentimento livre, do direito de abandonar a pesquisa. No caso desta pesquisa, como os/as colaboradores/as já tinham conhecimento das diretrizes da pesquisa, optamos por pedir a assinatura somente no reencontro, momento da validação dos textos transcriados.

A validação - que consiste na devolução do texto transcriado ao(à) colaborador(a) - possibilita um equilíbrio das forças na produção do texto escrito, mas também (Leite, 2008) explicita uma tensão entre colaborador(a) e pesquisador(a), uma vez que os depoimentos deverão ser legitimados pelo(a) colaborador(a). Esse momento, que Meihy denomina de conferência do texto final, exigirá do(a) pesquisador(a) sensibilidade e capacidade de negociação, principalmente, se o(a) colaborador(a) desejar abstrair trechos de sua história, considerados significativos à pesquisa.

Depois dos reencontros, foi realizado um entrelaçamento das entrevistas que, de acordo com Meihy $(1994$, p.52) é o que dá sentido social à história oral, buscando o diverso e o detalhamento das redes e seus aspectos divergentes, o entrelaçamento aqui é tecido entre os(as) professores(as), jovens e referencial teórico.

\section{Entrelaçando Experiências, Sentidos e Afetos}

As narrativas entrelaçadas ecoam as experiencias que influenciam diretamente na ação docente dos(as) professores(as). Aqui são apresentados fragmentos das histórias de vida ao passo que são realizadas análises e interlocução com as narrativas de adolescentes e com referencial teórico sobre os diferentes temas que emergem das experiencias e que consideramos apresentar relação com o objeto do estudo.

A infância é, ou deveria ser, uma fase do desenvolvimento humano de inúmeras brincadeiras, a adolescência com muitas descobertas e aprendizados desencadeados no seio da família e em diferentes grupos. Entretanto a realidade nem sempre é tão lúdica e acolhedora e contribui para a construção de outros estilos de vidas, outras práticas sociais.

Vários milhares de crianças e adolescentes estão, neste exato momento, circulando pelas ruas e por diversas instituições de assistência e proteção, apesar de terem pais e diversos parentes. Alguns serão reconduzidos aos seus lares; outros, se sobreviverem à vida nas ruas, serão encaminhados a abrigos, instituições de privação de liberdade, 
clínicas de desintoxicação e outros tipos de instituição e poderão nunca retornar às suas famílias (Rizzini et al., 2007, $\mathrm{p} .17)$.

Concebemos que a aproximação entre as histórias dos(as) jovens e professores(as), pode convergir com a hipótese lançada, sobretudo quando analisamos a instituição família, pois Mateus, Cilene, Carla, Ana Luiza e Abenilda foram criados(as) por uma família com configurações que destoam das tradicionais, com pai e mãe. A diferença entre professores(as) e a maioria dos(as) adolescentes foi a possibilidade de vínculo positivo com alguém ou com alguma prática social. Professor Mateus, por exemplo, se vinculou à capoeira e ao amor materno. Cilene, Carla, Ana Luiza eram amparadas pelas avós e Abenilda por seu tio, que era seu pai legítimo, contudo ocultava tal fato pela madrasta que tinha ciúme do relacionamento anterior de seu pai, estendendo esse sentimento à criança.

A professora Ana Luiza possui forte vínculo com seus descendentes e se emociona apenas ao citar seus nomes, orgulhando-se da trajetória que o filho estudioso seguiu. Ao ouvir a história de Ana Luiza - que foi criada por sua avó, após episódio de violência entre a família paterna e sua mãe - podemos vislumbrar o quão violenta pode ser a constituição de uma família. A professora Ana Luiza recebeu amparo e afeto de sua avó materna, que dela cuidou até que alcançasse o ensino superior, independência e autonomia. Ana Luiza aprendeu a sobreviver, pedindo sempre que necessário, negociando prazos para terem moradia, vida simples, itinerante fugindo do passado, os caminhos percorridos por ela eram de manutenção da vida.

A avó da Ana Luiza foi a referência em sua vida e suas orientações serviram para que ela educasse o seu filho no caminho inverso ao do consumismo, “[...] foi o meu exemplo de vida. E são exatamente os meus ensinamentos, o que falta para essas crianças, ensinar sobre o consumismo, por exemplo, eu ensinei meu filho a não ser consumista, não o levava no shopping. Eu o levava em livraria e ficávamos horas e horas, nós íamos ao cinema, coisa que a minha avó não fazia comigo, mas eu tentei dar uma melhorada nos ensinamentos dela".

Enquanto a professora Ana Luiza sobrevivia transitando por diferentes espaços com a sua avó, a professora Abenilda dedicava cuidados aos seus irmãos, filhos da nova configuração familiar paterna; limpando a casa, lavando roupa no rio e em ambos os casos com ingresso tardio na escola. Abenilda lutava e esperançava um dia entrar no Grupo Escolar, admirava a imagem da vizinha que era professora e que andava toda elegante e cheia de trabalhos dos(as) alunos(as) para avaliar, era uma boa professora e como diz Cunha (1989), serviu para que Abenilda se espelhasse nas boas práticas da professora.

As professoras Cilene e Carla se aproximaram de suas avós. Quando a professora Carla nasceu sua mãe era muito jovem e morava em cidade pequena, no qual moradores(as) pré-julgavam a maternidade precoce sem a presença paterna. A jovem grávida mudou-se para São Paulo, onde Carla nasceu; logo sua mãe arrumou um novo marido e com isso Carla, que não conhecera o pai, com seis meses de idade, sofreu abandono materno, foi destinada a residir com a avó na Bahia. Com isso, Carla cresceu aos cuidados dos avós, sofrendo com humilhação relacionada ao abandono de seus pais, aspecto que marcou sua trajetória, pois além dos colegas na escola, precisava tolerar comentários pejorativos de familiares; os únicos que conseguiram dar a sustentação que ela necessitava foram seus avós maternos: "Considero a minha avó a minha mãe, uma pessoa que me incentivou, que eu me espelho" (Professora Carla).

A professora Carla a partir do laço de rejeição (Sennett, 2012b), conseguiu criar uma imagem positiva do que seria autoridade, de maternidade e as responsabilidades advindas dessa experiência. A professora Cilene também foi criada pela avó até os seus 15 anos, mas não ficaram explícitas as razões que motivaram esse rearranjo familiar, mas ao contrário de Carla, essa passagem não é narrada com mágoas ou sentimento de abandono e salta em sua história para a nova constituição da família com a chegada do padrasto, que ela considera como pai, e também o irmão mais novo, fruto do novo casamento de sua mãe.

A condição de receber um teto, alimento, atenção e afeto por um familiar pode ser um diferencial na trajetória da criança e do(a) jovem. Rizzini et al. (2007), abordam a questão da importância da família para o desenvolvimento destes e 
destacam que há necessidade de criar formas de suporte à família para que consigam cuidar dos(as) filhos(as), superando o caráter assistencialista. Entretanto, estar no seio familiar não garante boas condições de existência, dada as diferentes formas de exploração que famílias submetem crianças e adolescentes, tais como o excesso de tarefas domésticas em detrimento dos estudos, abusos sexuais, trabalho no tráfico ou nos semáforos e outros modos de conquistar alguma renda por meio da exploração infanto-juvenil.

Enquanto a professora Abenilda era responsável por todas as tarefas domésticas, outro(as) professores(as) também estavam envolvidos(as) em atividades laborais desde a infância, o que denota o entrelaçamento histórico. Nas madrugadas, Maria também já estava de pé, trabalhava fazendo tijolos e ao amanhecer, ia para a escola, espaço numa configuração diferente da atual, mas possível à realidade da época. Maria logo parou de estudar para se dedicar ao trabalho e ajudar seus pais. A professora Estelita começou a trabalhar aos 13 anos na cantina de uma escola e logo também optou por parar de estudar para auxiliar sua mãe que trabalhava como faxineira.

O professor Cícero ajudava na plantação junto a seu pai e irmãos, aprendendo matemática com medidas de "braça", o respeito necessário para conviver em família com seus pais e catorze irmãos. A autoridade exercida pelo pai de Cícero sobre toda a família é algo notável, um olhar de soslaio era suficiente para dizer algo ou corrigir alguma conduta.

A autoridade é um conceito que transcende um limite imposto, mera supressão da autonomia e da individualidade do sujeito. Sennett $(2004 ; 2012$ b) equipara a autoridade com a figura de um maestro, o qual é capaz de guiar com disciplina todos os membros de uma orquestra com segurança, desenvoltura e competência, ou seja, a figura paterna de Cícero seria uma pessoa indispensável para a família, sendo responsável pelo sustento, por ensinar regras e zelar pelo cumprimento delas sem utilizar os meios de força para tal, conquistando, portanto, uma autoridade legitimada pelo restante da família.

Para Sennett a palavra vínculo tem um duplo sentido "É uma ligação, mas é também, como em servidão, um limite imposto. Nenhuma criança poderia evoluir sem o sentimento de confiança e amparo que provém da crença na autoridade de seus pais" (Sennett, 2012b, p.14).

Nesse sentido, a relação estabelecida entre os pares cria laços afetivos e por isso filhos(as) acreditavam que a figura paterna lhes transmitia sentimento de amparo. Se interpretasse a figura do pai como a de um tirano, talvez, ele estaria sendo rejeitado por cícero e então o sentimento pudesse ser o de solidão, uma emoção da ausência. Podemos ler esse "olhar de soslaio" como um desrespeito à autonomia dos filhos, entretanto segundo Sennett (2012a), é a maneira como interpretamos as crises que perpassam nossas vidas e as imagens de relações de força presentes em nossa vida.

Os/as responsáveis pelos/as professores/as Cícero, Cilene, Abenilda, Ana Luiza não tinham escolarização ou não haviam frequentado a escola até a conclusão da educação básica, com exceção do pai de Abenilda, todos valorizavam o ingresso e permanência no espaço escolar como garantia do jargão futuro melhor. O pai e a madrasta da Abenilda afirmavam que a escola não era necessária e que se aprendesse a ler e a escrever começaria a se corresponder com namorados. Portanto, ela iniciou a alfabetização com a professora que ministrava aula particular no período noturno, mesmo com recursos escassos e prosseguia ao regressar ao lar "[...] à noite, depois que arrumava toda a casa da minha tia, eu ficava estudando com aqueles candeeiros, sozinha, não podia ter amiga, ninguém, só eu lá estudando. Quando eu ia dormir, eu passava a mão no rosto e olhava, estava as marcas óleo queimado do candeeiro, mas eu fazia todas as lições, errado ou certo, eu fazia" (Professora Abelnilda).

Para a professora Abenilda era preciso certa persistência para poder aprender a ler e a escrever depois de um dia de muito trabalho e exploração por parte da cuidadora/tia/madrasta. A família com o arranjo burguês foi pertencente a uma minoria de professores(as), somente Walnir, Maria Lala, Luiza, Cícero tiveram presentes pai e mãe no processo de desenvolvimento infantil. Tal condição representou nessas vidas a possibilidade de estudar, ter referências positivas para ancorar as tomadas de decisão, todavia não significou que não tiveram que trabalhar ou se esforçar para conquistar os objetivos 
traçados. Todos(as) trabalharam em tenra idade.

A nascitura já pode ser considerada uma vitória para as professoras Ana Luiza, Sinhá e Maria Lala. A mãe da Ana Luiza sofria com a família paterna e corria riscos iminentes, a mãe da Maria Lala, por residir no campo, sofria com a carência de recursos para monitoramento da gestação e já havia perdido outros filhos. Já no caso de Sinhá, a mãe não queria mais filhos e tentou o aborto, sem sucesso, assim já lutava desde a gestação para sobreviver e mudar o seu mundo.

As experiências vivenciadas nas famílias do de Cícero, Maria Neuda, Abenilda, Luiza, Ana Luiza, Carla, Sinhá, Cilene e Mateus colaboraram para a migração para São Paulo. De municípios pequenos do interior do estado do Ceará vieram Cícero e Maria Neuda, ambos com condição estável, família "estruturada", com alimento e escolarização, contudo almejavam mais, queriam aprender cada vez mais e obter novas oportunidades. As professoras Abenilda e Cilene vieram do interior do estado de Pernambuco. Abenilda se casou e logo foi para São Paulo, mesmo com formação para lecionar, não conseguiu emprego, teve dificuldade em ministrar aulas e ao conseguir sofreu preconceito linguístico devido ao estado de nascitura. Cilene também enfrentou barreiras no mundo corporativo ao relacionar-se com pessoas mangando dela por utilizar expressões oriundas de sua criação com os avós pernambucanos, contudo aos poucos ela foi abandonando seu traço linguístico devido à orientação da chefia para poder se manter nos empregos, ou seja, foi necessário despir-se de sua identidade para ser tolerada no local de trabalho.

Abenilda ao iniciar sua primeira classe para lecionar em São Paulo, ensinava os(as) alunos(as) com resquícios da linguagem falada, ou seja, com pequenos erros gráficos. Na tentativa de reverter a situação a escola tentou retirar a professora do corpo docente e não mediu esforços para efetivar seu desligamento. Dialogou com cuidadores, forjou assinaturas e com isso a Abenilda quase foi retirada da escola fruto de um processo obscuro e preconceituoso.

A professora que ensinava a Maria Lala, era dotada de uma formação conservadora, ainda próxima daquela que fazia uso da palmatória, espetava a professora Maria Lala com uma caneta sempre que ela confundia a letra P com o B nos ditados. Quando relatou à sua mãe que não queria mais ir à escola, sua mãe estranhou até que descobriu o motivo e escreveu uma mensagem à professora "Quando a professora pegou meu caderno para corrigir a lição, estava lá o bilhete, eu nem sabia ler, primeira, segunda série, a professora leu, em vez de ela guardar e ser uma comunicação entre elas, não, ela foi e falou para a sala toda e num tom sarcástico disse para ninguém chegar perto de mim que eu era filhinha da mamãe e do papai, e que ninguém não podia mexer nela, não podia tocar, ressaltando para as crianças não me tocarem na hora do recreio, não brincarem comigo".

Pelo exposto, mudou-se de escola e sofreu bullying, pois utilizava a linguagem da zona rural ao mesmo tempo em que disponha de dedicação aos estudos e superava os(as) demais.

A adolescência chegou para Carla e Sinhá que desejavam aproveitar a vida para além dos municípios baianos. Viveram uma adolescência repleta de sonhos para além do espaço inserido e sabiam que próximo aos familiares seria inviável realizá-los. Enquanto Sinhá ficou com os irmãos, Carla ficou com a mãe, a qual tinha uma relação fria e repleta de mágoa. Sinhá ficaria em São Paulo por um espaço de tempo mínimo, todavia se recusou a voltar para a Bahia e, em logo casou-se. O mesmo aconteceu com Carla, que não conseguiu conviver com o novo arranjo familiar de sua mãe, então, optou pelo casamento, enquanto fuga. Carla e Sinhá se conheceram na Fundação e ali nasceu uma amizade.

O casamento provocou mudanças significativas nas vidas de Maria Neuda, Walnir e Luiza. A professora Maria Neuda que chegou em São Paulo aos 19 anos de idade e se casou aos 21 anos, trabalhou por um período em atividades distantes da docência, somente depois de ter duas filhas é que conseguiu realizar o curso superior de Letras, posteriormente Filosofia e continuou até a especialização. Na vida do professor Walnir o casamento mudou seu estilo de vida, assim como proporcionou o contato com a religião. O casamento também impulsionou Maria Lala para que fizesse o curso superior, além de outros cursos que ela almejava, sendo que somente após a maternidade iniciou os estudos na graduação em Matemática. 
A educação escolar na Febem e, posteriormente, na Fundação CASA foi a porta de entrada para a docência para Cícero, Maria Neuda, Sinhá, Estelita, Carla, Luiza, Maria Lala, Cilene, Mateus. As professoras Maria Neuda e Sinhá foram pioneiras, começaram ainda na fase da FEBEM, Maria Neuda ingressou assim que concluiu a faculdade e Sinhá ainda estudava quando iniciou o trabalho na secretaria escolar de uma unidade da Febem e, seguidamente, passou a exercer a função de professora.

\section{Considerações Finais}

As vidas dos(as) jovens marginalizados(as) socialmente, sejam negros(as), pobres, residentes às margens geográfica e social, são permeadas de abandono familiar, com constituição familiar repleta de (re)arranjos que deixam lacuna e uma questionável referência positiva que se apresente de fato como exemplo a ser seguido. A maioria dos/as professores(as) colaboradores(as) (9/12) desta pesquisa também sofreram com dificuldades na infância e adolescência.

As histórias de vidas desses(as) jovens são repletas de preconceitos ao qual são julgados(as) a todo instante, daí a importância de se compreender o cenário histórico amplo, avaliar com lucidez o que ocorre no mundo e dentro de nós. A imaginação sociológica é a capacidade de transpor de uma perspectiva a outra e se fundamenta na necessidade de conhecer o sentido social e histórico do indivíduo na sociedade (Mills, 1975), é o que auxilia o olhar a se despir do preconceito. A aproximação entre as histórias de vida dos/as professores/as com as histórias dos adolescentes em conflito com a lei é um fator que corrobora com a permanência de professores(as) no espaço escolar, um ambiente hostil.

Nesta esteira, a ausência de alguém que se importe e oriente no discernimento das escolhas, é um dos principais aspectos que distanciam jovens e professores(as), pois mesmo jovens que possuem algum apoio familiar, como vimos neste estudo, nem sempre têm tais referências como positivas, visto muitos serem presos ou explorados e forçados a buscarem alimento para toda a família, por meios ilícitos.

Os percursos trilhados pelos(as) professores(as) denotam persistência por formar uma família diferente daquelas constituídas por seus progenitores, de modo que pudessem garantir melhores condições aos(as) filhos(as), ou que simplesmente não reproduzissem violências sofridas. $\mathrm{O}$ mundo em que se insere a juventude não é estrangeiro aos(às) professores(as), conhecem os bairros onde vivem, coabitam os mesmos espaços, conhecem as limitações das escolas da rede, as dificuldades do município, a violência cotidiana que propicia o diálogo. No caso dos(as) depoentes da pesquisa, pertencem a bairros, em sua maioria, onde moram jovens que vivenciam problemas, logo não há como impedir, pelo contrário, a compreensão do quê e de como as coisas acontecem e favorecem o relacionamento interpessoal.

Enquanto professores(as) que lecionam no CI acolhem e buscam ser compreensivos(as) com a realidade vivida por cada jovem, a maioria das escolas vai na contramão, vivenciam a superlotação, péssimas condições laborais, disparidade da vida juvenil, dificultando, portanto, a imaginação sociológica e geradas para e na escola.

Há cooperação (Sennett, 2012a) no processo educativo, a juventude entende que a troca beneficia como possibilidade de aprendizado e é o caminho à liberação acelerada por dedicar-se aos estudos. A relação entre professores(as) e o espaço escolar da Fundação CASA também é atravessada pelas condições de trabalho ofertadas, alunos(as) vigiados(as), número reduzido de alunos(as) por classe e, no caso destes(as) professores(as), o respeito conquistado, pois nem todos(as) docentes conseguem tamanha façanha, sobretudo aqueles(as) que exigem respeito sem ofertar, simplesmente pela reverência à hierarquia. Nesta condição, o que presenciamos no cotidiano do CI é a presença da autoridade imposta, ausência de vínculo, relação rasa entre professores(as) e alunos(as) e sem ganhos efetivos, seria o que Sennett (2012b) denomina de autoridade paternalista, oferta afeto falso a subalternos(as), pois, para alguns(mas) o interesse educacional só importa à medida que atenda à permanência do lecionar.

Outra forma de refutar professores(as), é quando se valem, nas palavras de Freire (1996), da fórmula farisaica "faça o 
que mando e não o que eu faço". Professores(as) que (re)afirmam a necessidade de respeitar regras, cumprir os deveres e responsabilidades para se viver em sociedade, e, ao mesmo tempo não planejam suas aulas, despreparados(as) frente ao fazer docente, propiciando lacunas nos processos educativos pela prática social da indiferença, não recebem o mesmo tratamento que os(as) jovens dão àqueles(as) professores(as) quando denotam interesse em educar. "Ensinar exige a corporeificação das palavras pelo exemplo" (Freire, 1996, p.38).

O liame de confiança (Sennett, 2009) desenvolve-se à medida que o(a) jovem entende que pode depender da Educação para alcançar liberdade e melhores condições à sua permanência, com possibilidades de retornar aos espaços escolares, conseguir emprego, por exemplo. Enquanto, o(a) professor(a) também depende do educar para sua permanência como docente.

Doravante, postulamos que a qualidade das relações interpessoais entre alunos(as) e professores(as), apesar de toda vigilância à qual ambos estão submetidos(as), considera entrelaçamentos nas vidas dos(as) entrevistados(as) e alunos(as), em termos de igualdade social, logo, arriscamos afirmar que há, em momentos, o que Sennett (2004) denomina de "respeito mútuo", apesar das diferenças.

Esta pesquisa não é conclusiva, mas aponta para a necessidade de aprofundar a formação inicial no que tange aos Direitos Humanos, de tal modo que novas pesquisas podem ser direcionadas à formação de professores/as para a justiça social, pois a condição de oprimido dos/as docentes em tela favoreceu o sentimento de empática com o/a adolescente com histórias de vidas que mais se assemelham que distanciam.

\section{Referências}

Almeida, B. G. M. (2010). A experiência da internação entre adolescentes: práticas punitivas e rotinas institucionais. 177 fls, Dissertação (Mestrado em Sociologia) - Universidade de São Paulo.

Brasil (2016). Conselho Nacional de Educação. Resolução CNE/CEB n 3, de 13 de maio de 2016 - Define Diretrizes Nacionais para o atendimento escolar de adolescentes e jovens em cumprimento de medidas socioeducativas.

Brasil (2020). Lei 12.594, de 18 de janeiro de 2012. Institui o Sistema Nacional de Atendimento Socioeducativo (SINASE).

Campos, R. G., Machado, D. F., Quinelatto, R. F., \& Conceição, W. L. da. (2021). The impact of the socio-educational measure for freedom assisted in the self-organization of the youth's life project in conflict with the law. Research, Society and Development, 10(5), e9910514792. https://doi.org/10.33448/rsdv10i5.14792

Conceição, W. L. (2017a). Atendimento Socioeducativo: Atores e Atrizes de um Cenário em Movimento. Paco Editorial.

Conceição, W. L. D. (2017b). Histórias de vidas que se unem: a professora, o professor e os [elos com os] jovens infratores. 136fls. Tese (Doutorado em Educação) - Universidade Estadual de Campinas. http://repositorio.unicamp.br/jspui/handle/REPOSIP/322308

Conceição, W. L., Teixeira, J. D., \& Campos, R. G. (2020). Socioeducação. Olhares: Revista do Departamento de Educação da Unifesp, 8(2), 102-121. https://periodicos.unifesp.br/index.php/olhares/article/view/10625.

Cunha, M. I. (1989). O bom professor e sua prática. Papirus Editora.

Fernandes, M. N., \& Costa, R. P. (Org.) (2019). Socioeducação no Brasil: Intersetorialidade, desafios e referências para o atendimento, Nova Práxis Editorial.

Fonseca, D. C. (2013). Escolarização de adolescentes em privação de liberdade: análise do tema em uma amostra de periódicos. Revista Eletrônica de Educação, 7(1), 13-31.

Freire, P. (1996). Pedagogia da autonomia: saberes necessários à prática educativa. Paz e Terra.

Goffman, E. (2003). Manicômios, prisões e conventos. (7a ed.).

Guimarães, A. M. (2011). Vidas de jovens militantes. 416 fls. Tese (Livre Docência) - Universidade Estadual de Campinas.

Ireland, T. (2009). Vinte anos de Educação para Todos (1990-2009): um balanço da educação de jovens e adultos no cenário internacional. Em Aberto, 22(82).

Marzochi, A. S. (2014). História de vida dos jovens da Fundação Casa: o lugar da escola nessas vidas. 188fls. Dissertação (Mestrado em Educação) Universidade Estadual de Campinas. http://repositorio.unicamp.br/handle/REPOSIP/254093

Meihy, J. C. S. B. (1996). Manual de História Oral. Ed. Loyola. 
Meihy, J. C. S. B. (2008). Palavras aos jovens oralistas: entrevistas em história oral. Oralidades: Revista de História Oral. Núcleo de Estudos em História Oral, USP, Ano, 2.

Meihy, J. C. S. B., \& Holanda, F. (2013). História oral: como fazer, como pensar. (7a ed.). Contexto.

Mills, C. W. (1975). A imaginação sociológica. Zahar.

Moreira, F. M. (2011). Cadeias dominadas: dinâmicas de uma instituição em trajetórias de jovens internos. 2011. 186 fls. Dissertação. (Mestrado em Antropologia Social) - Universidade de São Paulo.

Müller, K. de A., Oliveira, U. P. de, \& Conceição, W. L. da. (2021). Ensino da educação física entre muros e grades: narrativas (auto)biográficas e reflexões compartilhadas. Cenas Educacionais, 4, e10773. https://revistas.uneb.br/index.php/cenaseducacionais/article/view/10773

Müller, Karine A. (2019). "O meu pouco, aqui é muito”! A educação física escolar na socioeducação. 2019. 151 fls. Dissertação (Mestrado em Educação Física) - Universidade Federal do Rio Grande do Sul.

Oliveira, U. P. de, Conceição, W. L., Oliveira, R. A. C., Grunnenvaldt, J. T., \& Reverdito, R. S. (2020a). O Esporte e o Lazer em Contextos de Medidas Socioeducativas no Brasil: Panorama e Análise da Produção Científica. LICERE - Revista Do Programa De Pós-graduação Interdisciplinar Em Estudos Do Lazer, 23(4), 249-277. https://doi.org/10.35699/2447-6218.2020.26680

Oliveira, U., Conceição, W., Grunnenvaldt, J., Olivera, R., \& Reverdito, R. (2020b). Esporte e lazer no plano individual de atendimento de adolescentes em cumprimento de medida socioeducativa de internação. Movimento (ESEFID/UFRGS), 26, e26054. https://doi.org/10.22456/1982-8918.101588

Oliveira, U. P., et al (2021). Adolescentes e conduta infracional: espaços, equipamentos e conteúdos de esporte e lazer. Movimento (ESEFID/UFRGS), e26079, <https://seer.ufrgs.br/Movimento/article/view/102733>.

Pereira, A. C. R., Quinelatto, R. F., \& da Conceição, W. L. (2021). História oral enquanto método possível nas pesquisas em direitos humanos. Cenas Educacionais, 4, e11279. https://www.revistas.uneb.br/index.php/cenaseducacionais/article/view/11279

Portelli, A. (1997). Tentando aprender um pouquinho: algumas reflexões sobre a ética na história oral. Projeto História: Revista do Programa de Estudos PósGraduados de História, 15.

Quinelatto, R. F. (2015). O programa de medidas socioeducativas em meio aberto: educação ou reprodução do aprendizado da rua? Tese, 235 fls. (Doutorado em Educação) - Universidade Federal de São Carlos.

Rizzini, I., Rizzini, I., Naiff, L., \& Baptista, R. Acolhendo crianças e adolescentes: experiências de promoção do direito à convivência familiar no Brasil.

Rolim, M. (2014). A formação de jovens violentos: para uma etiologia da disposicionalidade violenta. 246 fls. Tese (Doutorado em Sociologia) - Universidade Federal do Rio Grande do Sul.

Rovaron, M. (2017) Fundação CASA: o passado ditatorial no cotidiano democrático? 2017. 162 fls. Dissertação (Mestrado em Ciências Sociais) Universidade Estadual Paulista.

São Paulo (2017). Resolução Conjunta SE-SJDC 2, de 10-1-2017. Dispõe sobre o atendimento escolar a adolescentes e jovens em cumprimento de medidas socioeducativas de internação nos Centros de Internação - CI da Fundação CASA, e dá providências correlatas.

São Paulo (2017). Secretaria da Justiça e Defesa da Cidadania. Procedimentos para a garantia de acesso à educação básica aos adolescentes em cumprimento de medidas socioeducativas em meio fechado: orientações gerais aos servidores da SEE e da Fundação CASA.

Sennett, R. (2004). Respeito: a formação do caráter em um mundo desigual. Record.

Sennett, R. (2009). A corrosão do carácter: as consequências pessoais do trabalho no novo capitalismo. Record.

Sennett, R. (2012a). Juntos: os rituais, os prazeres e a política da cooperação. Record.

Sennett, R (2012b). Autoridade. Editora Record.

Teixeira, J. D. (2009). O sistema socioeducativo de internação para jovens autores de ato infracional do estado de São Paulo. 178fls. Dissertação (Mestrado em Educação). Universidade Federal de São Carlos.

Teixeira, J. D. (2015). Dos sujeitos e lugares da punição: da passagem do/a jovem perigoso/a para o/a jovem em perigo. Um estudo das dimensões do dispositivo da gestão dos riscos e de controle social da juventude. 252 fls. Tese (Doutorado em Ciências Sociais). Universidade Estadual Paulista.

Teixeira, J. D. (2017). Do Perigo ao risco. A gestão do controle da juventude no sistema socioeducativo de São Paulo. Cultura acadêmica. 